\title{
1 Radicals and Molecular Products from the Gas-Phase Pyrolysis of Lignin 2 Model Compounds. Cinnamyl Alcohol
}

3

4 Lavrent Khachatryan ${ }^{1 *}$, Meng-xia $\mathbf{X u}^{1}$, Ang-jian $\mathbf{W u}^{2}$, Mikhail Pechagin ${ }^{3}$, Rubik $5 \quad$ Asatryan $^{3}$

6

\author{
${ }^{1}$ Department of Chemistry, Louisiana State University, Baton Rouge, Louisiana 70803, USA \\ ${ }^{2}$ State Key Laboratory of Clean Energy Utilization, Institute for Thermal Power Engineering, \\ Zhejiang University, Hangzhou 310027, China \\ ${ }^{3}$ Department of Chemical and Biological Engineering, University at Buffalo, The State \\ University of New York, Buffalo, NY 14260, USA \\ * $\underline{1 \mathrm{khach} 1 @ 1 \text { su.edu }}$
}

13

\section{ABSTRACT}

The experimental results on detection and identification of intermediate radicals and molecular products from gas-phase pyrolysis of cinnamyl alcohol $(\mathrm{CnA})$, the simplest non-phenolic lignin model compound, over the temperature range of $400-800{ }^{\circ} \mathrm{C}$ are reported. The low temperature matrix isolation electron paramagnetic resonance (LTMI-EPR) experiments along with the theoretical calculations, provided evidences on the generation of the intermediate carbon and oxygen centered as well as oxygenlinked, conjugated radicals. A mechanistic analysis to explain formation of the major products from $\mathrm{CnA}$ pyrolysis; cinnamaldehyde, indene, styrene, benzaldehyde, 1-propynyl benzene, and 2-propenyl benzene is performed based on the density functional theory evaluated bond dissociation patterns and unimolecular decomposition pathways involving dehydrogenation, dehydration, 1,3-sigmatropic $\mathrm{H}$ migration, 1,2-hydrogen shift, $\mathrm{C}-\mathrm{O}$ and $\mathrm{C}-\mathrm{C}$ bond cleavage processes.

25 


\section{Introduction}

The renewable lignocellulosic biomass is a major alternative source of the fuel and chemicals benefitting from its vast abundance, economic efficiency, and $\mathrm{CO}_{2}$-neutral features.[1-3] One of the main components of biomass, lignin, is an amorphous, three dimensional branched polyphenolic polymer,

32 being synthesized via dehydrogenative polymerization of the three key cinnamyl alcohol-based monomers: $p$-coumaryl alcohol, coniferyl alcohol and sinapyl alcohol.[1, 4, 5] The pyrolysis of lignin coupled with various analytical and spectroscopic methods have been used over decades to get insight into the mechanism of its thermal decomposition.[2, 6-9] The distribution and chemical composition of the obtained condensed pyrolysates (primarily phenolic monomers and oligomers) have been found to be largely dependent on the reaction temperature, residence time, heating ramp, reactor types and biomass composition.[10-13]

The competing bond-cleavage channels ( $\alpha$ - and $\beta$ - alkyl-aryl ether, $\mathrm{C}-\mathrm{C}, \mathrm{C}-\mathrm{O}$ and $\mathrm{C}-\mathrm{OCH}_{3}$ bond scission), and various hydrogenation and hydrogenolysis processes, along with the molecular and free radical decomposition pathways, have been suggested to be the major elementary processes in the thermal

42 decomposition of lignin and formation of functional groups.[2, 14-16] Some of these processes are 43 expected to play also a significant role in bio-oil conversions. However, the nature of lignin, induced by 44 its complex structure, high molecular weight and complex compositional proportions of the cinnamyl 45 alcohol-based monomers, are the main reasons that the intricate pathways of lignin pyrolysis still remain 46 unexplored, in spite of their importance in potential biomass formation and practical applications.[1] 47 Therefore, the investigation on pyrolysis of relevant model compounds is prompted as a constructive 48 approach to disclose the complex nature of the lignin thermal decomposition.

49 Herein, we studied the pyrolysis of the simplest non-phenolic lignin model compound - cinnamyl 50 alcohol (CnA) (Fig. 1), which provides the main features of the basic lignin precursor monomers: $p$ 51 coumaryl, coniferyl and sinapyl alcohols. 
The main focus of this work is the detection and identification of the intermediate radicals generated

53 during the pyrolysis of $\mathrm{CnA}$ using the advantages of the low temperature matrix isolation -electron

54 paramagnetic resonance (LTMI-EPR) technique.[17] Furthermore, we provide the experimental results

55 and density functional theory (DFT) analysis of the possible decomposition pathways of CnA to form

56 major molecular products; cinnamaldehyde, indene, styrene, benzaldehyde, 1-propynyl benzene, and 2-

57 propenyl benzene. DFT results discussed in Sect. 3.4, are based on the detailed examination of the various

58 cross-sections of the potential energy surface (PES) of the CnA involving skeletal and peripheral bond

59 dissociation, as well as various isomerization reactions.

60

61 2. Materials and Methods

$62 \quad$ 2.1. Materials

The CnA (98\% purity) and PBN (N-tert-butylnitrone, minimum 98\% GC) were purchased

64 from the Sigma Aldrich, Inc. Ultra-high purity helium (99.99\%) was used as a carrier gas. A stock solution of 0.01 M CnA in acetone was used for pyrolysis experiments.

66

67

68

69

70

71

72

73

74

75

\subsection{Experimental Protocol for Pyrolysis}

The pyrolysis of $\mathrm{CnA}$ was investigated in the temperature range of $400-800{ }^{\circ} \mathrm{C}$, with $100{ }^{\circ} \mathrm{C}$ increment using the system for thermal diagnostic studies (STDS), as illustrated in Figure S1.[18, 19] The pyrolysis was conducted in an electrically heated micro-furnace, using a straight tubular, isothermal flow quartz reactor $(3.8 \mathrm{~mm}$ i.d.; $77.6 \mathrm{~mm}$ in length). A temperature controller (CN78000, Omega) was used to adjust the furnace temperature precisely. The micro-furnace was placed inside an Agilent 6890N gas chromatograph (GC) to keep the temperatures of the transfer lines $(1 \mathrm{~m} \times 0.53 \mathrm{~mm})$ and connections at $250{ }^{\circ} \mathrm{C}$ to avoid condensation of the effluents.[2] The residence time was maintained at $0.2 \mathrm{~s}$ by adjusting the gas flow rate to reduce the potential risks of secondary reactions. For each experiment, $5 \mu \mathrm{L} \mathrm{CnA} \mathrm{sample} \mathrm{(0.01} \mathrm{M}$ in acetone) was injected 
76 into the GC injector port by a syringe. Initially the port was purged with helium for 3 min at 80

$77{ }^{\circ} \mathrm{C}$ to sweep the acetone solvent out, and then programmed from $80{ }^{\circ} \mathrm{C}$ to $250{ }^{\circ} \mathrm{C}$ with the heating 78 ramp of $30{ }^{\circ} \mathrm{C} / \mathrm{min}$ to ensure the constant concentration of gas-phase sample vaporizing into the 79 reactor. In order to achieve the reproducibility of major products from pyrolysis, all the data were 80 the averaged values of two to three runs. In addition, blank experiments were performed to 81 confirm no residues were detained in the system.

\section{2}

\subsection{GC/MS Analysis of Pyrolysis Products}

The pyrolysates emerging from the reactor were condensed on the head of the GC capillary column at $-60{ }^{\circ} \mathrm{C}$ to cryogenically capture the products. The gas chromatography/mass spectroscopy (GC/MS) consisted of an Agilent $6890 \mathrm{~N}$ gas chromatography coupled with a $5973 \mathrm{~N}$ mass selective detector (MSD). A DB5-MS capillary column $(30 \mathrm{~m} \times 0.25 \mathrm{~mm} \times 0.25$ $\mu \mathrm{m})$ was used to separate and analyze the molecular products. The split mode was used with a ratio of $10: 1$. The temperature of the oven was programmed from the initial value of $-60{ }^{\circ} \mathrm{C}(5$ min hold) followed by a heating rate of $15^{\circ} \mathrm{C} / \mathrm{min}$ to $130{ }^{\circ} \mathrm{C}(1 \mathrm{~min}$ hold $)$ and then heated at a ramp of $25{ }^{\circ} \mathrm{C} / \mathrm{min}$ to $300{ }^{\circ} \mathrm{C}$ ( 5 min hold). The temperatures of GC injector and MSD detector were set as 240 and $280^{\circ} \mathrm{C}$, respectively. Total ion current mode (TIC) was used to quantify the products from CnA pyrolysis with a mass range of 15-600 amu. The products were identified based on the NIST library (NIST 98 version 1.6d) and the retention time of the individual compounds.

\subsection{EPR Measurements.}

A technique referred to in the literature as LTMI-EPR, was used in this study.[20-24] LTMIEPR allows accumulation and detection of trace quantities of radicals during the gas-phase processes. An electrically heated reactor interfaced to a liquid nitrogen-cooled Dewar located in 
the cavity of an EPR spectrometer was used for the pyrolysis of CnA. Reagents were pumped using rotary pumps at a pressure of $<0.3$ torr through the electrically heated pyrolysis zone. Due to the high boiling point of $\mathrm{CnA}$, the vaporizer was held at room temperature. The carbon dioxide carrier gas was used as a supporting matrix to assist in the freezing of radicals. The details of cryogenic trapping of radicals at low pressures can be found elsewhere.[17]

$$
\text { To further explore the nature of free radicals, a solid phase ( } N \text {-t-butyl- } \alpha \text {-phenylnitrone, PBN) }
$$
spin trapping technique was used at pyrolysis temperature of $800{ }^{\circ} \mathrm{C}$. [25-27] Approximately 20 mg powdered PBN was placed in the center of an EPR $4 \mathrm{~mm}$ quartz tube (hold from both sides by quartz wool) connected to the CnA pyrolysis vacuum line and located at the center of the EPR cavity. The $\mathrm{N}_{2}$ carrier gas was saturated by $\mathrm{CnA}$ vapor, entered into the pyrolysis zone at total pressure $\sim 0.3$ torr, and then passed through the tube loaded with solid PBN. The EPR signal was appeared in 5 minutes (vide infra, Fig. 4).

The EPR spectra were recorded on a Bruker EMX-20/2.7 EPR spectrometer (Bruker Instruments, Billerica MA) with dual cavities, X-band (100 kHz) and microwave frequency at 9.516 GHz. The typical parameters were: sweep width $200 \mathrm{G}$, EPR microwave power from 0.5 to $64 \mathrm{~mW}$, modulation amplitude $\leq 4 \mathrm{G}$, and time constant and sweep time in most cases were $10.24 \mathrm{~ms}$ and $167.77 \mathrm{~s}$, respectively.

The dimensionless magnetic moment of a radical, g-factor (a characteristic value which measures how the magnetic environment of unpaired electrons differ from that of a free, gasphase electron, $g=2.0023$ ) was calculated using Bruker's WINEPR program, which is a comprehensive line of software, allowing control of the EPR spectrometer, data-acquisition, automation routines, tuning and calibration on a Windows-based PC.[28] The exact g-values for key spectra were determined by comparison with a 2, 2-diphenyl-1-picrylhydrazyl (DPPH) 
122 standard. In some experiments, gradual warming of the Dewar was employed to allow annealing 123 of the matrix and annihilation of mobile or reactive radicals. This resulted in cleaner, sharper 124 spectra of single radicals under environmentally isolated conditions.

\section{2.5. Computational Details.}

126 Various decomposition pathways of $\mathrm{CnA}$ and relevant intermediates were computed using 127 non-local Kohn-Sham density functional theory based on the generalized gradient 128 approximation. The hybrid B3PW91 functional[29, 30] is employed in conjunction with the 129 moderate Pople-type basis set $6-31+\mathrm{G}(2 \mathrm{~d}, \mathrm{p})$ augmented with diffuse and polarization 130 functions.[31] This method is well tested in literature, and has also been evaluated in our 131 previous studies on open-shell systems.[32, 33] All quantum mechanical calculations are 132 performed using Gaussian 03 software[34] to obtain optimal equilibrium geometries and 133 transition states verified by vibration mode analysis. The energetic diagrams are based on 134 electronic energies corrected with zero-point vibrational energies. Gibbs free energies at different 135 temperatures are also provided, wherever a temperature dependence of the selected reactions is 136 analyzed (see Tables S3 and S4 in Supporting Information).

\section{$138 \quad$ 3. Results and Discussion}

139 The LTMI-EPR is a powerful tool for in situ exploration of radical processes.[17] However, 140 the identification of trapped radicals in some cases is challenging when a combination of two or 141 more species are involved. The apparent g-value (the maximum point of the integrated curve), in 142 particular, does not provide a conclusive structural information when the EPR spectrum is a 143 convolution of two or more species. The radical constituents of a mixture can only be 
144 distinguished through a judicious variation of the experimental conditions (temperature, pressure,

145 and annealing parameters, etc.) followed by computer analysis of the digitally stored spectra.

146 Such a procedure as well as an auxiliary - spin trapping experiments were employed here to

147 simplify the interpretation on the EPR spectra of gas-phase radicals trapped from CnA pyrolysis

148 over the wide temperature range.

\subsection{Radicals from Pyrolysis of $\mathrm{CnA}$ at 400 to $800{ }^{\circ} \mathrm{C}$}

A strong anisotropic EPR signal was detected from the gas-phase pyrolysis of CnA during the entire temperature range of 400 to $800{ }^{\circ} \mathrm{C}$, Figs. 2a and $2 \mathrm{c}$.

\section{The anisotropy is generally caused by the superposition of two or more spectra, easily seen in} annealing experiments reported elsewhere.[17, 35] However, no drastic changes in EPR spectra have been detected here during the annealing experiments at liquid nitrogen temperature. It is apparent that the radicals detected from high temperature pyrolysis of $\mathrm{CnA}$ (at $800{ }^{\circ} \mathrm{C}, \mathrm{Fig} .2 \mathrm{c}, \mathrm{d}$ ) are more persistent based on the fact that g-value remains unchanged up to $240 \mathrm{~s}$ of annealing time, while the radicals collected from the pyrolysis at $500{ }^{\circ} \mathrm{C}$ annihilated easily at $180 \mathrm{~s}$, Fig. 2a, b.

The persistent radicals at $800{ }^{\circ} \mathrm{C}$ most probably are O-centered which are more resistant to self-recombination than carbon centered radicals [36-38] and hence stable to annihilation (Fig. 2d). Whereas the carbon-centered counterparts are readily annihilated (Fig. 2b) and perhaps dominate at low temperatures of pyrolysis (vide infra). The g-value undergoes significant changes during the annealing processes from 2.0085 to 2.0060 at $500^{\circ} \mathrm{C}$, and from 2.0096 to 2.0045 at $800{ }^{\circ} \mathrm{C}$, indicating possibly, the existence of the mixture of different radical species.

Another candidate to explain the anisotropy of the observed EPR spectra could serve the alkylperoxy radical $\left(\mathrm{RO}_{2}\right)$ readily formed in the presence of trace amounts of oxygen[39] and 
167 described by a high g-value between 2.008 and 2.010.[39, 40] However, the formation of $\mathrm{RO}_{2}$ 168 traces was ruled out based on the power dependence experiments, Fig. 3. Namely, the EPR signal 169 for radicals from $\mathrm{CnA}$ pyrolysis is saturated at low (<10 mW) microwave power (Fig. 3), 170 whereas $\mathrm{RO}_{2}$ radicals from gas phase oxidation of simple hydrocarbons are saturated at 171 microwave powers as high as $40 \mathrm{~mW}$.[41] The fact that the saturation behavior of radicals 172 collected at pyrolytic temperatures of $500{ }^{\circ} \mathrm{C}$ and $800{ }^{\circ} \mathrm{C}$ are somewhat different, Fig. 3, provides 173 an additional evidence on the mixed character of the spectra. The last statement is in full accord 174 with the theoretical results discussed later in the text.

\section{3.2. Spin Trapping Experiments.}

The EPR spectrum presented in Fig. 4 obtained from the spin trapping experiments consists of 177 six lines. The hyperfine splitting constants $\left(\alpha^{\mathrm{N}}=13.8 \mathrm{G}\right.$ and $\left.\alpha^{\mathrm{H}}=2.18 \mathrm{G}\right)$ obtained for the PBN178 radical adduct were closer to the values reported for the oxygen-centered radicals $\left(\mathrm{RO}: \alpha^{\mathrm{N}}=\right.$

$\left.17913.6 \mathrm{G}, \alpha^{\mathrm{H}}=1.56 \mathrm{G} ; \mathrm{RO} \cdot+\mathrm{ArCO}_{2}: \alpha^{\mathrm{N}}=13.9 \mathrm{G}, \alpha^{\mathrm{H}}=2.00 \mathrm{G}\right)$, than the carbon-centered radicals $180\left(\mathrm{R} \cdot: \alpha^{\mathrm{N}}=15.2 \mathrm{G}, \alpha^{\mathrm{H}}=3.85 \mathrm{G}\right) .[42,43]$ Note that the EPR spectra presented in Fig. 4 were only 181 detected in oxygen free vacuum system.

182 A spectrum with 3 broad lines and characteristic peaks of adsorbed oxygen was detected in 183 the presence of traces of oxygen, Figure S2 (Supporting Information). Further pumping down the 184 system to $10^{-3}$ torr regenerates the signal in Fig. 4, when the oxygen peaks disappeared.

185 These experimental findings indicate that the anisotropy of the EPR signals detected during 186 the CnA pyrolysis, can clearly be assigned to oxygen-centered radical(s).

\section{3.3. Molecular Product Analysis.}

The overall effect of the pyrolysis temperature on the distribution of primary products is

189 illustrated in Fig. 5. The pyrolysis products, mainly aromatic and oxygenated aromatic 
190 hydrocarbons are listed in Table S1 (Supporting Information) and further categorized into two 191 groups: the major products, including cinnamaldehyde, indene, styrene, benzaldehyde, 1192 propynyl benzene, 2-propenyl benzene, and minor products, with the proportion less than $1 \%$ in 193 total TIC count, i.e., benzene, ethyl benzene, phenylacetylene and methyl benzene.

194 The dominance of the cinnamaldehyde over other products (more than $50 \%$ of total products) 195 was observed at low temperature, $400{ }^{\circ} \mathrm{C}$. A drastic decrease of its proportion of the total 196 products (from $74 \%$ to $16 \%$ ) was observed when the temperature increased from $400{ }^{\circ} \mathrm{C}$ to 700 $197{ }^{\circ} \mathrm{C}$. The proportions of cinnamaldehyde and benzaldehyde are initially increased with 198 temperature, achieving the maximum of $10 \%$ and $7 \%$ at $600{ }^{\circ} \mathrm{C}$, respectively, and then declined 199 with further enhancement of the temperature. Thus, the major low-temperature product is 200 cinnamaldehyde and its content gradually exhausted at $800^{\circ} \mathrm{C}$. Except for indene, with traces at $201400{ }^{\circ} \mathrm{C}$, all other products are formed at elevated temperatures.

202 In the category of aromatic hydrocarbons, the benzene, 2-propenyl- and 1-propynyl- benzene, 203 show the variation tendency similar to those observed for cinnamaldehyde and benzaldehyde, 204 and approached the maxima at $600{ }^{\circ} \mathrm{C}$, whereas the indene and styrene exhibited maxima at 700 $205{ }^{\circ} \mathrm{C}$. Further deoxygenation of $\mathrm{CnA}$ and newly formed cinnamaldehyde is prevailed at higher 206 temperatures, leading to the formation of the hydrocarbon pyrolysates such as styrene, 2207 propenyl benzene, and 1-propynyl benzene. In addition, the indene is formed, perhaps via a 208 dehydration of CnA followed by spontaneous cyclization of adduct, vide infra.

\subsection{Potential Energy Surface (PES) Analysis}

Generally, the pyrolysis of systems similar to those considered in this paper is expected to 211 involve various bond dissociation and unimolecular transformation channels, including 
212 hydrogenation, dehydrogenation and hydrogenolysis of the skeletal C-C and C-O bonds.[16, 44]

213 Here, we discuss some relevant pathways to form experimentally observed main products based

214 on the calculated potential energy profiles and bond dissociation patterns. Some secondary

215 processes are also considered and described during the discussion on the possible pathways to

216 primary products.

\section{3.4.1. Molecular Pathways to Primary Products}

218 Theoretically explored unimolecular decomposition and isomerization pathways (selected cross-sections of the PES) for CnA to potentially form experimentally identified major products

220 are illustrated in Fig. 6 and described by

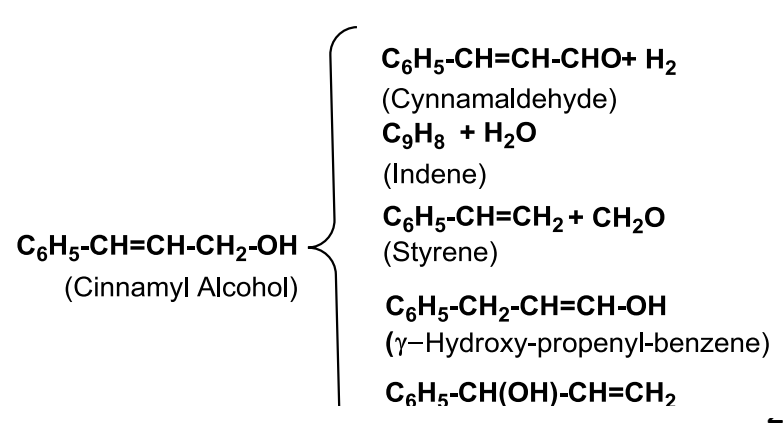
reactions $(1)-(5)$.

(2) Reactions (1) - (3) directly form relevant

(3) products cinnamaldehyde, indene and

(4) styrene through the straightforward

(5) dehydrogenation,

$\alpha-$

226 dehydration/cyclization and 1,3-H-migration reactions of $\mathrm{CnA}$, respectively.

227 No direct single-step pathways are identified to form two other products 2-propenyl benzene 228 (2-PBz) and benzaldehyde (BzAld). Instead, two additional transition states are located on the

229 respective PES involving 1,3-sigmatropic $\mathrm{H}$ - and 1,3-sigmatropic $\mathrm{OH}$-migration processes, 230 which generate two isomeric hydroxyl-derivatives of CnA via reactions (4) and (5), respectively. 231 Note that these two isomerization processes are entropically less favored compared to the 232 defragmentation of CnA via reactions (1) - (3), vide infra.

As expected for molecular reactions, all calculated decomposition barriers are fairly high and 234 can be afforded only at elevated temperatures. Due to the entropy gain from the fragmentation of 
235 molecules, the unimolecular channels (1) - (3) can principally account for the formation of the experimentally observed primary products, styrene and indene.

237 However, according to theory, the cinnamaldehyde, which also is the dominant low238 temperature pyrolysis product of $\mathrm{CnA}$ (Fig. 5), cannot be formed via a straightforward 239 dehydrogenation, since its barrier is significantly higher than those for other products generated 240 at even higher temperatures ( $c f$. Fig. 6). The electronic energy barrier is $79.0 \mathrm{kcal} / \mathrm{mol}$, whereas 241 the enthalpy of activation at room temperature is somewhat lower at $78.8 \mathrm{kcal} / \mathrm{mol}$ (the enthalpy 242 diagram is provided in Figure S3, Supporting Information). Due to the entropy lose at TS, the 243 Gibbs free energy of activation at the same temperature is $80.1 \mathrm{kcal} / \mathrm{mol}$, and increased to 83.2 $244 \mathrm{kcal} / \mathrm{mol}$ at $527{ }^{\circ} \mathrm{C}$ ( Table 3, Supporting Information). The initially endergonic by $2.91 \mathrm{kcal} / \mathrm{mol}$ 245 reaction (1) becomes exergonic (thermodynamically preferred) starting from about $327{ }^{\circ} \mathrm{C}$, as 246 follows from corresponding Gibbs free energies presented in Table S4.

247 Notably, no typical hydrogenation and hydrogenolysis products of $\mathrm{CnA}$, such as the 248 hydroxy-propyl benzene $\left(\mathrm{C}_{6} \mathrm{H}_{5}-\mathrm{CH}_{2} \mathrm{CH}_{2} \mathrm{CH}_{2} \mathrm{OH}\right)$ and $\beta$-methyl styrene $\left(\mathrm{C}_{6} \mathrm{H}_{5}-\mathrm{CH}=\mathrm{CH}\right.$ $249 \mathrm{CH}_{3}$ ), respectively, are seen during gas-phase pyrolysis, as opposed to that obtained in $250 \mathrm{Pd} / \mathrm{Al}_{2} \mathrm{O}_{3}$-catalyzed $\mathrm{CnA}$ decomposition processes.[45] This could suggest that dihydrogen 251 product is liberated insignificantly viz., the dehydrogenation of the CnA reactant occurs 252 inefficiently in gas-phase pyrolysis.

253 Thus, the dominant formation of cinnamaldehyde at low temperature $\left(400{ }^{\circ} \mathrm{C}\right)$, cannot be 254 merely explained by direct dehydrogenation of $\mathrm{CnA}$ (reaction 1), but it most likely occurs via 255 secondary processes involving the radical intermediates, as will be advocated in the next section. 256 Formation of some other products, such as styrene, benzaldehyde and ethylene also can be 257 explained via radical reactions, which generally require lower activation energies and can occur 
258 at low and moderate temperatures.

259 It should be emphasized that the intrinsic barrier from cis- $\mathrm{CnA}$ is somewhat lower at $\Delta \mathrm{E}^{\#}=$ $26069.0 \mathrm{kcal} / \mathrm{mol}$, compared to the relative energy of TS1 in regard to the entrance channel indicated 261 in Fig. 6. However, the formation of indene via dehydration (reaction 2) requires an initial 262 isomerization of the cinnamyl alcohol reactant to cis-CnA, since it predominantly exists in more 263 stable (by $3.1 \mathrm{kcal} / \mathrm{mol}$ ) trans configuration. Thus, formation of the cis-CnA will be accelerated 264 with temperature, and could also contribute in explaining why the indene yield reaches a 265 maximum value at higher temperatures $\left(700{ }^{\circ} \mathrm{C}\right.$, Fig. 5). The Gibbs free energy analysis shows 266 that the temperature enhancement does not affect the free energy barrier $\left(\Delta G^{\#}\right)$ for this reaction 267 (2) due to the insignificant entropy lose at TS, as opposed to those seen for other pathways 268 (Table S4). Moreover, this decomposition reaction is exergonic even at room temperature $\left(\Delta \mathrm{G}_{\mathrm{rxn}}\right.$ $269=-17.93 \mathrm{kcal} \mathrm{mol}^{-1}$ ), whereas the other decomposition reactions become exergonic only at 270 elevated temperatures ( $c f$. Table 4$)$.

271 The unimolecular reaction (3), leading to the elimination of formaldehyde from CnA, could 272 partly explain also the styrene formation at high temperatures $\left(\Delta \mathrm{E}^{\#}=67.1 \mathrm{kcal} / \mathrm{mol}\right.$, Fig. 6). Note 273 that the formaldehyde is one of the major light products in the gas fraction of the lignin 274 pyrolysis.[7] Our preliminary analysis shows that a radical pathway can be involved in the 275 styrene production to explain the higher content of the styrene at $700{ }^{\circ} \mathrm{C}$. The same process may 276 occur with 1-propynyl benzene.

277 A possible rearrangement of the $\gamma$-hydroxy-propenyl benzene $(\gamma$-HPBz) formed from 1,3 278 sigmatropic H-migration in $\mathrm{CnA}$ (reaction 4) via a barrier of $72.3 \mathrm{kcal} / \mathrm{mol}$ (see, Fig. 6), can 279 potentially generate 2-propenyl-benzene radical $\left(\mathrm{C}_{6} \mathrm{H}_{5} \mathrm{CH}_{2} \mathrm{CH}=\mathrm{C}(\mathrm{H})^{\bullet}\right)$. However, dissociation 280 energy of hydroxyl group of $\gamma-\mathrm{HPBz}$ is fairly high at $93.8 \mathrm{kcal} / \mathrm{mol}$. Perhaps, a bimolecular $\mathrm{OH}-$ 
281 abstraction reaction could contribute to the further formation of the significant amounts of 2282 propenyl-benzene (Fig. 5).

283 Similarly, dehydration of 3-phenyl-1-propanol $\left(\mathrm{C}_{6} \mathrm{H}_{5} \mathrm{CH}_{2} \mathrm{CH}_{2} \mathrm{CH}_{2} \mathrm{OH}\right)$ could serve as a 284 possible channel to generate the observed 2-propenyl-benzene (2-PrBz). However, the lack of the 285 main hydrogenation adduct 3-phenyl-1-propanol in gas-phase processes (vide supra), which is

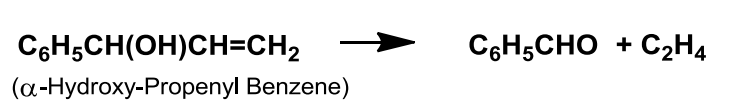

(6) well presented in catalyzed pyrolysis L४/ of $\mathrm{CnA}$ by $\mathrm{Pd} / \mathrm{Al}_{2} \mathrm{O}_{3}$, (45) again

288 289

290

291

292

293

294

295

296

297

298

299

300

301

302

303

304

suggests that the concentration of dihydrogen or a suitable hydrogen donor is marginal, and thus, this pathway also is less likely to occur in gas-phase pyrolysis to generate 2-PrBz.

Reaction (5) describes 1,3-sigmatropic $\mathrm{OH}$-transfer to the $\mathrm{C} 7$ center to form $\alpha$-hydroxy propenyl benzene ( $\alpha$-HPBz, Fig.6). Further H-migration could generate benzaldehyde and ethylene. Benzaldehyde is well presented in pyrolysis products at moderate temperatures (Fig. 5). Activation energy of the unimolecular reaction (5) is well moderate $(62.2 \mathrm{kcal} / \mathrm{mol})$, whereas further decomposition of $\alpha-\mathrm{HPBz}$ to form benzaldehyde and ethylene via a 1,2-H-transfer (reaction 6), requires higher activation energy of $74.4 \mathrm{kcal} / \mathrm{mol}$.

Due to the small entropy changes between the intermediate and TS, the activation Gibbs fee energy remains almost the same as the electronic energy barrier at $\Delta \mathrm{G}^{\#}=74.43 \mathrm{kcal} \mathrm{mol}^{-1}$. On the other hand, a significant entropy gain occurs during the reaction $\left(\Delta \mathrm{S}_{\mathrm{rxn}}=38 \mathrm{cal} / \mathrm{K}\right.$.mol $)$ to form two product species benzaldehyde and ethylene. Therefore, the temperature enhancement increases the rate of this elementary reaction (6). It should be emphasized that most of the unimolecular decomposition pathways, along with the bond dissociation channels discussed in the next section, generate two product species, and thus are almost equally preferred entropically compared to the isomerization reactions (4) and (5) which are endergonic at reaction operating 
temperatures (see Tables S3 and S4).

To summarize, there are a variety of molecular channels to originate primary products, however they are mostly energy demanding and indirect and more feasible pathways should be invoked to explain the low-energy formation of dominant products.

\subsubsection{Some Relevant Radical Pathways}

The primary radicals during gas phase pyrolysis of $\mathrm{CnA}$ can be generated via straightforward bond dissociation channels. Fig. 7 provides the major bond fission channels, involving the $\mathrm{C}-\mathrm{H}$, $\mathrm{C}-\mathrm{O}$ and skeletal C-C bonds, to form CnA-derived primary radicals. The values correspond to electronic energies corrected with zero-point vibrational energies. The corresponding enthalpy and Gibbs free energy diagrams are provided in Figures S5 and S6 in Supporting Information, respectively. Furthermore, these radicals can be generated more feasibly via relevant bimolecular reactions involving available radical pool.

The cleavages of the skeletal C-OH and $\mathrm{C}(9)-\mathrm{H}$ bonds to form conjugated (viz., stabilized) 1phenylallyl $\mathrm{R}(\mathrm{PhA})$ and hydroxy-phenyl-allyl radicals $\mathrm{R}(\mathrm{C} 9)$, are most favored decomposition processes with bond dissociation energies (BDE) being as low as 66.8 and $69.2 \mathrm{kcal} / \mathrm{mol}$, respectively (Fig. 7). Further transformations of these radicals are a priori expected to originate main pathways to the primary products.

Thus, from Fig. 7 clearly follows that the radicals $\mathrm{R}(\mathrm{PhA})$ and $\mathrm{R}(\mathrm{C} 9)$ can be dominant species at low temperature pyrolysis of $\mathrm{CnA}$, while the oxygen centered radical $\mathrm{R}(\mathrm{O} \bullet)$ will prevail at elevated temperatures. The oxygen-centered radicals are known to possess higher g-values, compared to those for carbon-centered ones [17]. The g-value of free electron (2.0023) in such systems is shifted upward by virtue of the heteroatom (in this case, oxygen), which is known to increase the spin-orbit coupling that results in increased g-values.[46, 47]. 
To distinguish the radical species registered in experiments, some theoretical calculations

329 were performed for g-tensors of key radicals based on the Neese's coupled-perturbed DFT 330 methodology implemented in Gaussian 03 program. [48, 49]

331 Presented in Table 1 data, indeed, demonstrated that the O-centered CnA-radical R(O•), Fig. 7

332 generated via cleavage of the $\mathrm{C}(9) \mathrm{O}-\mathrm{H}$ bond, possesses the highest $\mathrm{g}_{\text {iso }}$ of $2.0159-2.0207$,

333 depending on the employed method and basis set, whereas isotropic g-values calculated for C-

Table 1. Isotropic g-Values for Intermediate Radicals Calculated at Different DFT Levels

\begin{tabular}{|c|c|c|c|c|c|c|}
\hline \multirow[b]{2}{*}{ Radical } & \multirow[b]{2}{*}{ Notation } & \multicolumn{5}{|c|}{$g_{\text {iso }}{ }^{\mathrm{a}}$} \\
\hline & & $\begin{array}{l}\text { B3LYP/ } \\
\text { BS-I }^{\mathrm{b}}\end{array}$ & $\begin{array}{l}\text { B3LYP/ } \\
\text { BS-II }^{b}\end{array}$ & $\begin{array}{l}\text { B3PW91/ } \\
\text { BS-I }^{\text {b }}\end{array}$ & $\begin{array}{l}\text { B3PW91/ } \\
\text { BS-II }^{\mathrm{b}}\end{array}$ & $\begin{array}{l}\text { B3LYP/ } \\
\text { BS-III }^{b}\end{array}$ \\
\hline $\mathrm{C}_{6} \mathrm{H}_{5} \mathrm{C}(\mathrm{H})=\mathrm{C}(\mathrm{H})-\mathrm{C}\left(\mathrm{H}_{2}\right)\left(\mathrm{O}_{0}\right)$ & $\mathbf{R}(\mathbf{O} \bullet)$ & 2.0165 & 2.0172 & 2.0159 & 2.0168 & 2.0207 \\
\hline $\mathrm{C}_{6} \mathrm{H}_{5} \mathrm{C}\left(\mathrm{H}_{2}\right)-\mathrm{C}_{\cdots}^{\prime} \stackrel{\mathrm{O}}{\mathrm{H}} \mathrm{O}_{(\mathrm{H})}$ & $\mathrm{C}_{6} \mathrm{H}_{5} \mathrm{CH}_{2}\left(\mathrm{CHCHO}^{\circ}\right.$ & 2.0055 & 2.0056 & 2.0052 & 2.0054 & 2.0063 \\
\hline $\mathrm{C}_{6} \mathrm{H}_{5} \mathrm{C}(\mathrm{H}) \cdots \mathrm{C}(\mathrm{H})=\mathrm{C}(\mathrm{H})(\mathrm{OH})$ & $\mathbf{R}(\mathbf{C 9})$ & 2.0029 & 2.0030 & 2.0029 & 2.0030 & 2.0030 \\
\hline $\mathrm{C}_{6} \mathrm{H}_{5} \mathrm{C}(\mathrm{H}) \stackrel{\cdots}{\cdots} \mathrm{C}(\mathrm{H})=\mathrm{C}\left(\mathrm{H}_{2}\right)$ & $\mathbf{R}(\mathbf{P h A})$ & 2.0026 & 2.0027 & 2.0026 & 2.0026 & 2.0027 \\
\hline
\end{tabular}

334 centered radicals, such as $\mathrm{R}(\mathrm{C} 9)$, is much lower around $2.0029-2.0030$. The conjugated O-

335 linked radical $\mathrm{C}_{6} \mathrm{H}_{5} \mathrm{CH}_{2}(\mathrm{CHCHO})^{\bullet}$ possesses an intermediate g-value of ca. 2.006. As expected,

336 g-values for highly delocalized C-centered radicals $\mathrm{R}(\mathrm{C} 7)$ and $\mathrm{R}(\mathrm{C} 8)$ are close to the g-value of

337 free electron: 2.0024 and 2.0022, respectively. These data are in accord with conclusions from

338 experimental results discussed above and detailed below.

\subsubsection{Dominance of the oxygen-linked radicals at low temperatures}

340 The cryogenic experiments (Figs. 2 and 3) revealed that EPR signals from gas-phase pyrolysis

341 of $\mathrm{CnA}$ are characterized by high g-values (>2.008), which indicates the dominance of the 342 oxygen-centered radicals. Direct formation of the most straightforward O-centered radical $\mathrm{C}_{6} \mathrm{H}_{5^{-}}$ 
$\mathrm{R}(\mathrm{C9}) \rightarrow \mathrm{C}_{6} \mathrm{H}_{5} \mathrm{CH}_{2}(\mathrm{CHCHO})^{\bullet}$

$\mathrm{C}_{6} \mathrm{H}_{5} \mathrm{CH}_{2}(\mathrm{CHCHO})^{\bullet} \rightarrow \mathrm{C}_{6} \mathrm{H}_{5}-\mathrm{CH}=\mathrm{CH}-\mathrm{CHO}+\mathrm{H}$
(7)

(8)

$343 \mathrm{CH}=\mathrm{CH}-\mathrm{CH}_{2} \mathrm{O}^{\bullet}$ denoted as $\mathrm{R}\left(\mathrm{O}^{\bullet}\right)$, requires higher $\mathrm{BDE}=97.5 \mathrm{kcal} / \mathrm{mol}$, as shown in Fig. 7.

344 Further decomposition of $\mathrm{R}\left(\mathrm{O}^{\bullet}\right)$ leads to the low-energy formation of the formaldehyde and 345 styrene radical $\left(\Delta \mathrm{E}^{\#}=25.5 \mathrm{kcal} / \mathrm{mol}\right)$. This channel could well contribute to the formation of 346 styrene, but not the one for the low-temperature product cinnamaldehyde.

347 Formation of the dominant product cinnamaldehyde at low-temperature $\left(400{ }^{\circ} \mathrm{C}\right)$, as it occurs 348 in heterogeneous catalytic reactions (45), cannot be simply explained by direct dehydrogenation 349 of $\mathrm{CnA}$ via reaction (1) due to the high barrier of activation $\left(\Delta \mathrm{E}^{\#}=79.0 \mathrm{kcal} / \mathrm{mol}\right.$, Fig. 6$)$. On the 350 other hand, the isomerization of the more feasibly formed carbon-centered 3-hydroxy-1351 phenylallyl radical denoted as R(C9) (Fig.7) followed by further H-elimination could provide a 352 reasonable explanation.

353 Indeed, the PES analysis presented above shows a feasible formation of the R(C9) radical 354 through a $\mathrm{C}(9)-\mathrm{H}$ bond scission $(\mathrm{BDE}=69.2 \mathrm{kcal} / \mathrm{mol})$. A further rearrangement of this radical, 355 into an oxygen-linked isomeric radical $\mathrm{C}_{6} \mathrm{H}_{5} \mathrm{CH}_{2}(\mathrm{CHCHO})^{\bullet}$ (Table 1) via reaction (7) is proven to 356 be a low energy process illustrated in Fig. 8.

357 Further feasible formation of cinnamaldehyde, as a major low temperature product of 358 pyrolysis at $400{ }^{\circ} \mathrm{C}$, can either occur via $\mathrm{H}$-atom removal of the generated radical, reaction (8), 359 with $\mathrm{BDE}(\mathrm{C} 7-\mathrm{H})=37.6 \mathrm{kcal} / \mathrm{mol}$, or via $\mathrm{H}$-abstraction by another radical.

360 The radical $\mathrm{C}_{6} \mathrm{H}_{5} \mathrm{CH}_{2}(\mathrm{CHCHO})^{\bullet}$ (referred here as oxygen-linked radical due to a partial 361 location of the spin density on O-atom) is probably the dominant intermediate in the mixture 362 registered by EPR at moderate temperatures. DFT calculations demonstrated a $\mathrm{g}_{\text {iso }}=2.0051$ 3632.0063 (Table 1) for this radical that combines the terminal oxygen and the proximal (C9) carbon 
atoms in one active center, referred to in this paper as O-linked radicals. This resembles the vicinal O-atom effect on g-value of a radical referred in literature as a "carbon centered radical with vicinal oxygen" $[47,50,51]$.

In fact, carbon centered radicals (such as $\mathrm{R}(\mathrm{C} 9)$ with calculated $\mathrm{g}_{\text {iso }}=2.0029$, and $\mathrm{R}(\mathrm{PhA})$ with calculated $\left.\mathrm{g}_{\text {iso }}=2.0026(7)\right)$ and oxygen-linked $\mathrm{C}_{6} \mathrm{H}_{5} \mathrm{CH}_{2}(\mathrm{CHCHO})^{\bullet}$ radical with calculated $\mathrm{g}_{\text {iso }}=2.0051-2.0063$ ) are major active species at lower pyrolysis temperatures. Due to the competition of the reactions while increasing of temperature (Fig.7), it is reasonable to expect formation of the mixtures of different radicals (with overlapped, "average" g value) evidencing that the plausible pyrolysis pathways of $\mathrm{CnA}$ involve different carbon, oxygen centered as well as oxygen-linked radicals.

Described above dehydrogenation mechanism of $\mathrm{CnA}$ can be prevalent phenomenon involving pyrolysis of other natural organic sources. Dehydrogenation of monolignol end groups $\left(-\mathrm{CH}=\mathrm{CH}-\mathrm{CH}_{2} \mathrm{OH}\right)$ of the lignin structure, indeed, is known to occur during the pyrolysis of biomass, as well as the pyrolysis of lignin itself [52] and can be explained via the radicalmolecular mechanism provided in this work.

Certainly, this mechanism is at variance with the chemical transformation of CnA into cinnamaldehyde, which easily occurs in nature catalyzed by cinnamyl alcohol dehydrogenase (CAD) enzyme,[53, 54] as well as the catalytic conversions of $\mathrm{CnA}$ over the typical dehydrogenation catalysts such as $\mathrm{Pd} / \mathrm{Al}_{2} \mathrm{O}_{3}$ at moderate temperatures (e.g., $275{ }^{\circ} \mathrm{C}$ ), as particularly shown by Grunwaldt and co-workers. [45]

\subsubsection{Other Relevant Radical Pathways to Primary Products.}

As indicated above, the straightforward dehydroxylation of CnA to form 1-phenylallyl radical, $\mathrm{R}(\mathrm{PhA})$, is the lowest-energy bond dissociation channel $(\mathrm{BDE}=66.8 \mathrm{kcal} / \mathrm{mol})$ and can 
contribute to the formation of the 2-propenyl-benzene (2-PBz). The high delocalization and some reactivity features of this radical have recently been studied by Sebree et al. using DFT-B3LYP and IR-spectroscopy analyses. [55] Intriguingly, it has been suggested to play a potential role in the formation of polyaromatic hydrocarbons (particularly in Titan atmosphere), perhaps due to the ambident nature of its reactivity

The distribution of unpaired electrons in the radicals have long been considered as an index of reactivity to predict the reaction pathways and branching ratios in the homologous series of $\mathrm{H}$ atom abstraction reactions and photochemical processes, as well as for the propagation steps in the radical polymerization processes.[56-60] Similarly, the computed spin densities have been employed to understand the regioselectivity of the radical-radical coupling of the phenoxyl-type radicals by us (37), as well as closely related monolignol radicals by other researchers.[37, 6166]

The Mulliken population analysis performed in current study, indeed, demonstrated that the two conjugated radical-centers are located at the $\mathrm{C} 7$ and $\mathrm{C} 9$ atoms of the 1-phenylallyl radical, and thus the radical is stabilized by resonance. Such an ambident radical could further abstract a hydrogen atom via both active C-centers from any H-donor species, such as the well-presented reagent $\mathrm{CnA}$ either. A branching can occur to form either 2-propenyl-benzene (also called 3phenyl-1-propene), or 1-propenyl-benzene (1-phenyl-1-propene) isomers via $\mathrm{H}$-addition to the C7 and C9 active centers, respectively. The higher density of the unpaired electron on C7-center compared to the one on the C9-center (53\% vs. $47 \%$ ) indicates the superior reactivity of the C7atom of the radical to account for the significant yields of 2-PBz observed in our experiments at $600{ }^{\circ} \mathrm{C}$ (Fig. 5). 


\section{$410 \quad 4 . \quad$ Conclusions}

411 The cinnamyl aldehyde (CnA) constitutes the simplest precursor and structural model of the

412 lignin end-groups and its thermal decomposition can shed a light into the intricate reactions of

413 the biomass formation and pyrolysis. The experimental LTMI-EPR data reported in this paper in 414 conjunction with the DFT-analysis of the possible transformation pathways provided a radical415 molecular mechanism for primary product formation during the pyrolysis of $\mathrm{CnA}$. The dominant 416 formation of the cinnamaldehyde at low-temperatures, due to the high barrier of the 417 dehydrogenation reaction in the gas-phase, cannot be explained via straightforward 418 dehydrogenation of $\mathrm{CnA}$, as it feasibly occurs in heterogeneous and biocatalytic reactions. A 419 radical mechanism is invoked based on the analysis of the intermediate radical species detected 420 by EPR spectroscopy using the low-temperature matrix isolation and spin-trapping techniques. 421 The registered open-shell species are suggested to be dominantly containing O-centered radicals, 422 due to the high g-values of the radicals over the range of the studied temperature $\left(400-800^{\circ} \mathrm{C}\right)$, 423 in full accord with theoretically evaluated isotropic g-values of the respective radicals.

\section{$425 \quad$ Acknowledgements}

426 This work was funded by National Science Foundation under Grant CBET 1330311. Dr. 427 Lavrent Khachatryan is grateful to Superfund Research Program (\#2P42ES013648-03), and Dr. 428 Meng-xia Xu - to RJ Reynolds' Tobacco Company, for partial support. Ruckenstein fund (SUNY 429 Buffalo) is acknowledged by Dr. Rubik Asatryan for continuous support. 
433 1. Chu, S., A.V. Subrahmanyam, and G.W. Huber, The Pyrolysis Chemistry of a Beta-O-4

434

435

436

437

438

439

440

441

442

443

444

445

446

447

448

449

450

451

452

453

454

455

456

457

458

459

460

461

462

463

464

465

466

467

468

469

470

471

472

473

474

475

476

Type Oligomeric Lignin Model Compound. Green Chem., 2013. 15(1): p. 125-136.

2. Kibet, J., L. Khachatryan, and B. Dellinger, Molecular Products and Radicals from Pyrolysis of Lignin. Environ. Sci. Technol., 2012. 46: p. 12994-13001.

3. Stanley, J.N.G., et al., Reactions of p-Coumaryl Alcohol Model Compounds with Dimethyl Carbonate. Towards the Upgrading of Lignin Building Blocks. Green Chem., 2013. 15(11): p. 3195-3204.

4. Dorrestijn, E., Laarhoven,L. J.J., Arends,I. W.C.E., Mulder,P., The occurrence and reactivity of phenoxyl linkages in lignin and low rank coal. J.Anal.Appl.Pyrolysis, 2000. 54: p. 153-192.

5. Baliga, V., et al., Physical characterization of pyrolyzed tobacco and tobacco components. Journal of Analytical and Applied Pyrolysis, 2003. 66(1-2): p. 191-215.

6. Shen, D.K., et al., Online Evolved Gas Analysis by Thermogravimetric-Mass Spectroscopy for Thermal Decomposition of Biomass and its Components under Different Atmospheres: Part I. Lignin. Bioresour. Technol., 2013. 130: p. 449-456.

7. Jakab, E., et al., Thermogravimetry Mass-Spectrometry Study of 6 Lignins within the Scope of an International Round-Robin Test. J. Anal. Appl. Pyrol., 1995. 35(2): p. 167179.

8. Patwardhan, P.R., R.C. Brown, and B.H. Shanks, Understanding the Fast Pyrolysis of Lignin. Chemsuschem, 2011. 4(11): p. 1629-1636.

9. Bussandri, A. and H. van Willigen, FT-EPR Study of the Wavelength Dependence of the Photochemistry of Phenols. J. Phys. Chem. A, 2002. 106(8): p. 1524-1532.

10. Zhou, S., et al., Effect of the Fast Pyrolysis Temperature on the Primary and Secondary Products of Lignin. Energy Fuels, 2013. 27(10): p. 5867-5877.

11. Zhang, M., et al., Pyrolysis of Lignin Extracted from Prairie Cordgrass, Aspen, and Kraft lignin by Py-GC/MS and TGA/FTIR. J. Anal. Appl. Pyrol., 2012. 98: p. 65-71.

12. Shen, D.K., et al., The pyrolytic degradation of wood-derived lignin from pulping process. Bioresource Technology, 2010. 101(15): p. 6136-6146.

13. Amen-Chen, C., H. Pakdel, and C. Roy, Production of Monomeric Phenols by Thermochemical Conversion of Biomass: A Review. Bioresour. Technol., 2001. 79(3): p. 277-299.

14. Brezny, R., V. Mihalov, and V. Kovacik, Low-Temperature Thermolysis of Lignins .1. Reactions of Beta-O-4 Model Compounds. Holzforschung, 1983. 37(4): p. 199-204.

15. Jakab, E., O. Faix, and F. Till, Thermal Decomposition of Milled Wood Lignins Studied by Thermogravimetry Mass Spectrometry. J. Anal. Appl. Pyrol., 1997. 40-1: p. 171-186.

16. Runnebaum, R.C., et al., Catalytic conversion of compounds representative of ligninderived bio-oils: a reaction network for guaiacol, anisole, 4-methylanisole, and cyclohexanone conversion catalysed by Pt/gamma-Al2O3. Catalysis Science \& Technology, 2012. 2(1): p. 113-118.

17. Khachatryan, L., et al., Formation of Cyclopentadienyl Radicals from the Gas-Phase Pyrolysis of Hydroquinone, Catechol, and Phenol. Environ. Sci. Technol., 2006. 40: p. 5071-5076.

18. Rubey, W.A. and R.A. Grant, Design Aspects of a Modular Instrumentation System for Thermal Diagnostic Studies. Rev. Sci. Instrum., 1988. 59(2): p. 265-269. 
19. Sidhu, S.S., et al., The homogeneous, gas-phase formation of chlorinated and brominated dibenzo-p-dioxin from 2,4,6-trichloro- and 2,4,6-tribromophenols. Combustion and Flame, 1995. 100(1/2): p. 11-20.

20. Nalbandyan, A.B. and A.H. Mantashyan, The elementary processes in slow gas-phase reactions. Inst. Chem.Phys. NA of Armenia, 1975: p. Yerevan, Armenia.

21. Khachatryan, L., Niazyan, O., Manashyan, A, Vedeeneev, V., Teiltelboim, M., Experimental determination of the equilibrium constant of the reaction methyl + oxygen. dblawr. methylperoxy during the gas-phase oxidation of methane. Int. J. Chem. Kin., 1982. 14: p. 1231-1241.

22. Carlier, M., Pauwels, J.P., and Sochet, L-R., Application of ESR techniques to the study of gas-phase oxidation and combustion phenomena. Oxidation Communication, 1984. 6(1-4): p. 141-156.

23. Davidson, I.M.T., Ellis, A.M., Mills, G.P., Pennington,M., Povey, I.M., Raynor, J.B., Russell, D.K., Saydam, S., Workman, A.D.,, Mechanism of pyrolysis of organometallic deposition precursors. J.Mater.Chem., 1994. 4: p. 13.

24. Mach, K., Mills, G.P., Raynor, J.B.,, Low pressure pyrolysis of hexamethyldisilane:ESR identification of radical intermediates. J.Organometallic Chemistry, 1997. 532: p. 229233.

25. Janzen, E.G. and Blackbur.Bj, Detection and Identification of Short-Lived Free Radicals by an Electron Spin Resonance Trapping Technique. Journal of the American Chemical Society, 1968. 90(21): p. 5909-5910.

26. Janzen, W.A., and Blackburn, B.J., Detection and identification of short-lived free radicals by ESR trapping technique. J.Am.Chem.Soc., 1969. 91: p. 4481-4493.

27. Janzen, E.G. and I.G. Lopp, Detection and Identification of Gas-Phase Free-Radicals by Electron-Spin Resonance Spin Trapping. Journal of Physical Chemistry, 1972. 76(14): p. 2056-\&.

28. Eaton, G.R., et al., Quantitative EPR. 2010. SpringerWienNewYork(Germany): p. 185.

29. Becke, A., D. . Density-functional thermochemistry. III The role of exact exchange J Chem Phys, 1993. 98 SRC - GoogleScholar: p. 5648-5652.

30. Perdew, J.P. and Y. Wang, Accurate and Simple Analytic Representation of the ElectronGas Correlation-Energy. Physical Review B, 1992. 45(23): p. 13244-13249.

31. Binkley, J.S., J.A. Pople, and W.J. Hehre, Self-Consistent Molecular-Orbital Methods .21. Small Split-Valence Basis-Sets for 1st-Row Elements. Journal of the American Chemical Society, 1980. 102(3): p. 939-947.

32. Asatryan, R., J.W. Bozzelli, and E. Ruckenstein, Dihadrogen Catalysis: A degradaion mechanism for N2-Fixation intermediates. J.Phys.Chem. A, 2012. 116: p. 11618-11642.

33. Harvey, J.N. and R. Poli, Computational study of the spin-forbidden H-2 oxidative addition to 16-electron Fe(0) complexes. Dalton Transactions, 2003(21): p. 4100-4106.

34. Frisch, M.J., et.al, Gaussian 03, Revision D.01, in Gaussian, Inc., Wallingford CT, 2004. 2004.

35. Khachatryan, L., Adounkpe, J., and Dellinger, B., Formation of Phenoxy and cyclopentadienyl radicals from the gas-phase pyrolysis of phenol. J.Phys.Chem., A, 2008. 112: p. 481-487.

36. Wiater, I., J.G.P. Born, and R. Louw, Products, rates, and mechanism of the gas-phase condensation of phenoxy radicals between 500-840 K. Eur.J.Org.Chem., 2000(6): p. 921928. 
37. Asatryan, R., Davtyan, A., Khachatryan, L., Dellinger, B., Molecular Modeling Studies of the Reactions of Phenoxyl Radical Dimers: Pathways to Polychlorinated Dibenzofurans. J. Phys Chem. A, 2005. 109(49): p. 11198-11205.

38. Altarawneh, M., et al., Mechanisms for formation, chlorination, dechlorination and destruction of polychlorinated dibenzo-p-dioxins and dibenzofurans (PCDD/Fs). Progress in Energy and Combustion Science, 2009. 35(3): p. 245-274.

39. Khachatryan, L., J. Adounkpe, and B. and Dellinger, Radicals from the Gas-Phase Pyrolysis of Hydroquinone 2. Identification of Alkyl Peroxy Radicals. Energy \& Fuel, 2008. 22: p. 3810-3813.

40. Svistunenko, D.A., R.P. Patel, and, and M.T. Wilson, An EPR investigation of human methaemoglobin oxidation by hydrogen peroxide: Methods to quantify all paramagnetic species observed in the reaction. Free Rad.Res.,, 1996. 24(4): p. 269-280.

41. Carlier, M. and L.-R. Sochet, A Kinetic Study of the Reactivity of Peroxy Radicals in the Oxidation of Methane and Higher Hydrocarbons, using E.S.R. J. Chem. Res., 1977. 5(6): p. 134-135.

42. Arroyo, C.M., et al., Spin Trapping of Oxygen and Carbon-Centered Free-Radicals in Ischemic Canine Myocardium. Free Radical Biology and Medicine, 1987. 3(5): p. 313316.

43. Pryor, W.A., K. Terauchi, and W.H. Davis, Electron-Spin Resonance (Esr) Study of Cigarette-Smoke by Use of Spin Trapping Techniques. Environmental Health Perspectives, 1976. 16(Aug): p. 161-176.

44. De Bruycker, R., et al., An experimental and kinetic modeling study of $\gamma$-valerolactone pyrolysis. Combustion and Flame, 2015.

45. Caravati, M., et al., Continuous catalytic oxidation of solid alcohols in supercritical CO2: A parametric and spectroscopic study of the transformation of cinnamyl alcohol over Pd/Al2O3. Journal of Catalysis, 2006. 240(2): p. 126-136.

46. Graf, F., Loth, K., and Gunthard, H-H., Chlorine hyperfine splittings and spin density distribution of peroxy radicals. An ESR and Quantum chemical study. Helvetica Chimica Acta., 1977. 60(76): p. 710-721.

47. Barclay, L.R.C., Cromwell, G.R., Hilborn, J.W., Photochemistry of a model lignin comound. Spin trapping of primary products and properties of an oligomer. Can.J.Chem., 1994. 72: p. 35-41.

48. Perdew, J.P. and Y. Wang, Accurate and Simple Analytic Representation of the ElectronGas Correlation-Energy. Phys. Rev. B, 1992. 45(23): p. 13244-13249.

49. Neese, F., Prediction of electron paramagnetic resonance g-values by coupled perturbed Hartree-Fock and Kohn-Sham theory. J. Chem. Phys. , 2001(115): p. 11080-11096.

50. Maskos, Z., L. Khachatryan, and B. Dellinger, Formation of the Persistent Primary Radicals from the Pyrolysis of Tobacco. Energy \& Fuel, 2008. 22(2): p. 1027-1033.

51. Maskos, Z. and B. Dellinger, Radicals from the oxidative pyrolysis of tobacco. Energy \& Fuels, 2008. 22(3): p. 1675-1679.

52. Kuroda, K., Analytical pyrolysis products derived from cinnamyl alcohol-end groups in lignins. Journal of Analytical and Applied Pyrolysis, 2000. 53(2): p. 123-134.

53. Li, X., et al., Biochemical characterization and identification of a cinnamyl alcohol dehydrogenase from Artemisia апnиa. Plant Science, 2012. 193: p. 85-95. 
54. Sun, Y., et al., Molecular cloning and biochemical characterization of two cinnamyl alcohol dehydrogenases from a liverwort Plagiochasma appendiculatum. Plant Physiology and Biochemistry, 2013. 70: p. 133-141.

55. Sebree, J.A., et al., Spectroscopy and ionization thresholds of pi-isoelectronic 1phenylallyl and benzylallenyl resonance stabilized radicals. Chemical Science, 2011. 2(9): p. 1746-1754.

56. Vasserman, A.L. and A.L. Buchachenko, Kinetics of reactions of stable radicals with various spin densities on the reaction centers. Bull. Acad. Sci. USSR, Div. Chem. Sci., 1967. 16: p. 1869-1872.

57. Martensson, O. and G. Karlsson, Pi-Electron Spin Densities of Lignin Constituents. Arkiv. Kem., 1969. 31(1): p. 5-16.

58. Asatryan, R.S., et al., Quantum-Chemical Study of the Mechanism of Radical Polymerization of Substituted Vinyl Acetylenes. Polymer Science USSR, 1985. 27(12): p. 2831-2836.

59. Breton, G.W. and K.R. Hoke, Application of Radical Cation Spin Density Maps toward the Prediction of Photochemical Reactivity between N-Methyl-1,2,4-triazoline-3,5-dione and Substituted Benzenes. Journal of Organic Chemistry, 2013. 78(10): p. 4697-4707.

60. Saouma, C.T. and J.M. Mayer, Do spin state and spin density affect hydrogen atom transfer reactivity? Chemical Science, 2014. 5(1): p. 21-31.

61. Russell, W.R., et al., Oxidative Coupling during Lignin Polymerization is Determined by Unpaired Electron Delocalization with Parent Phenylpropanoid Radicals. Arch. Biochem. Biophys., 1998. 333(2): p. 357-366.

62. Sangha, A.K., et al., Radical Coupling Reactions in Lignin Synthesis: A Density Functional Theory Study. Journal of Physical Chemistry B, 2012. 116(16): p. 4760-4768.

63. Durbeej, B. and L.A. Eriksson, Spin distribution in dehydrogenated coniferyl alcohol and associated dilignol radicals. Holzforschung, 2003. 57(1): p. 59-61.

64. Shigematsu, M., et al., Transition state leading to beta- $O$ ' quinonemethide intermediate of p-coumaryl alcohol analyzed by semi-empirical molecular orbital calculation. Journal of Wood Science, 2006. 52(2): p. 128-133.

65. Shigematsu, M. and H. Masamoto, Solvent effects on the electronic state of monolignol radicals as predicted by molecular orbital calculations. Journal of Wood Science, 2008. 54(4): p. 308-311.

66. Elder, T., Application of computational chemistry to lignin pyrolysis. Abstracts of Papers of the American Chemical Society, 2010. 239. 


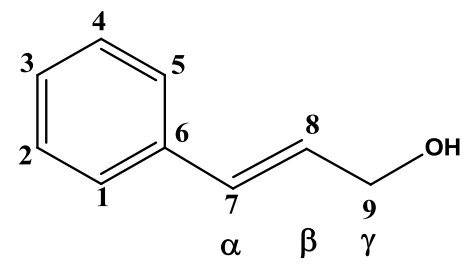

Fig. 1. Molecular structure of cinnamyl alcohol (CnA).

bU8

609 
(a)

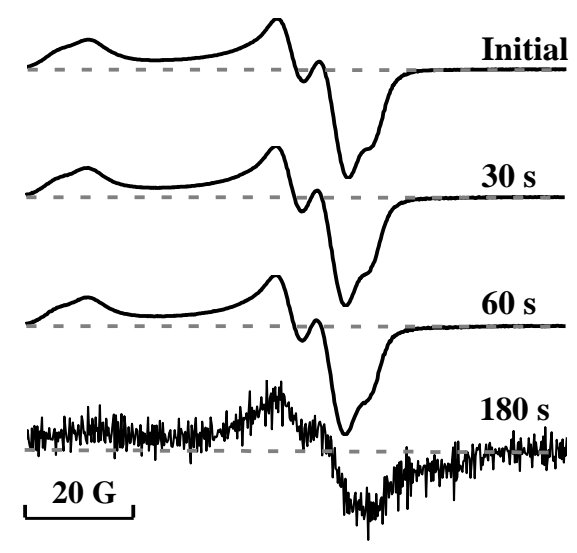

(c)

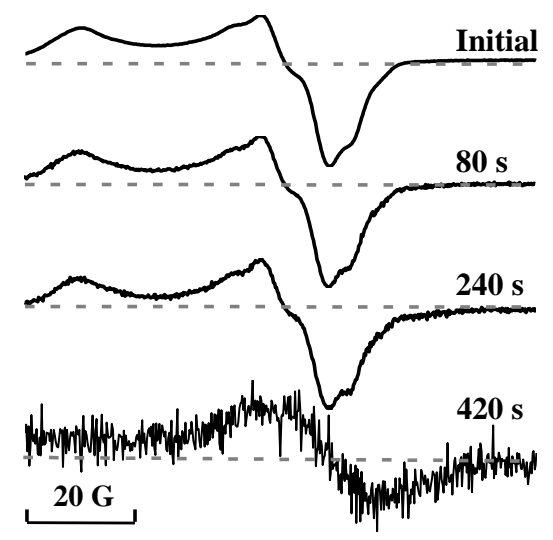

(b)

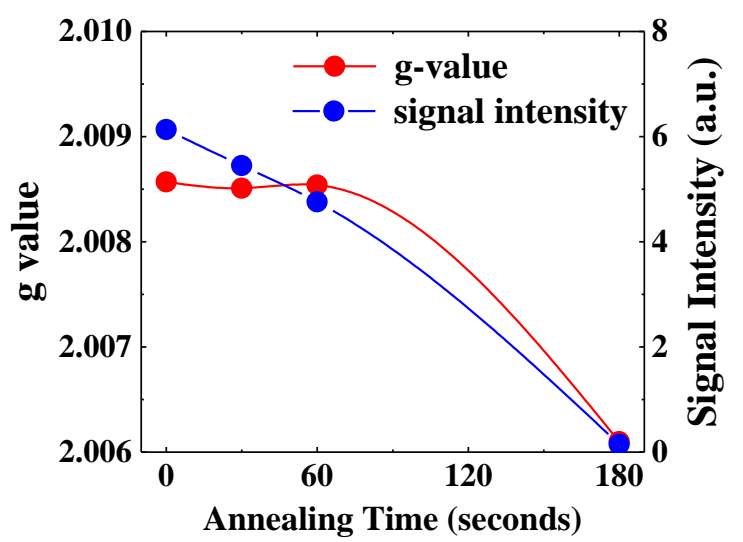

(d)

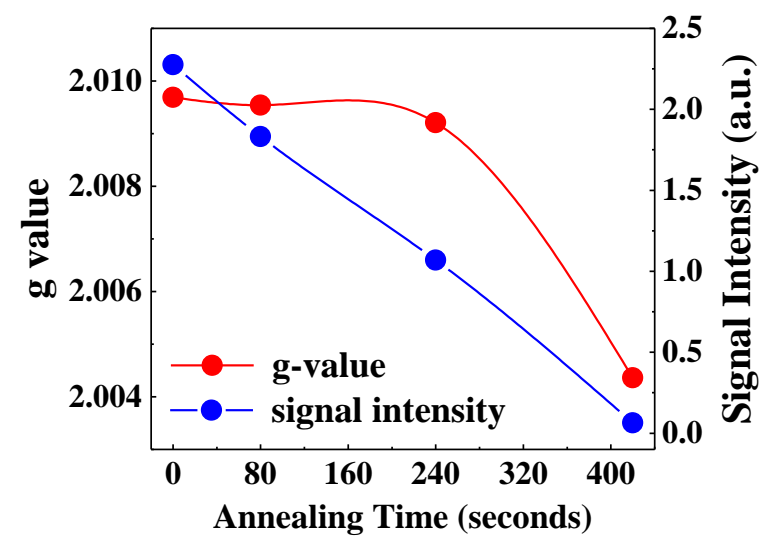

Fig. 2. Annealing effect on EPR spectra of radicals trapped at $77 \mathrm{~K}$ from gas-phase pyrolysis of CnA at $500{ }^{\circ} \mathrm{C}(\mathrm{a})$ and $800{ }^{\circ} \mathrm{C}(\mathrm{c})$. The g-value and intensity changes at $500{ }^{\circ} \mathrm{C}(\mathrm{b})$ and $800{ }^{\circ} \mathrm{C}(\mathrm{d})$. 


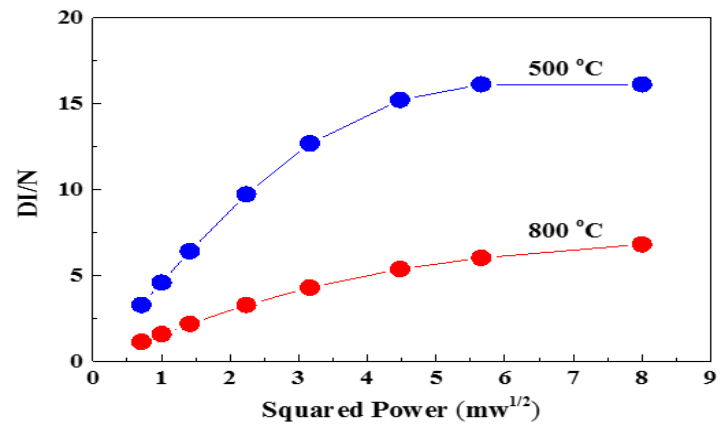

Fig. 3. Microwave power dependence of the EPR spectra detected at $77 \mathrm{~K}$ from $\mathrm{CnA}$ pyrolysis at $500{ }^{\circ} \mathrm{C}$ and $800{ }^{\circ} \mathrm{C}$. $\mathrm{DI} / \mathrm{N}$ value is the double integrated (DI) intensity of the EPR spectrum that has been normalized (N) to account for the conversion time, receiver gain, number of data points, sweep width. 


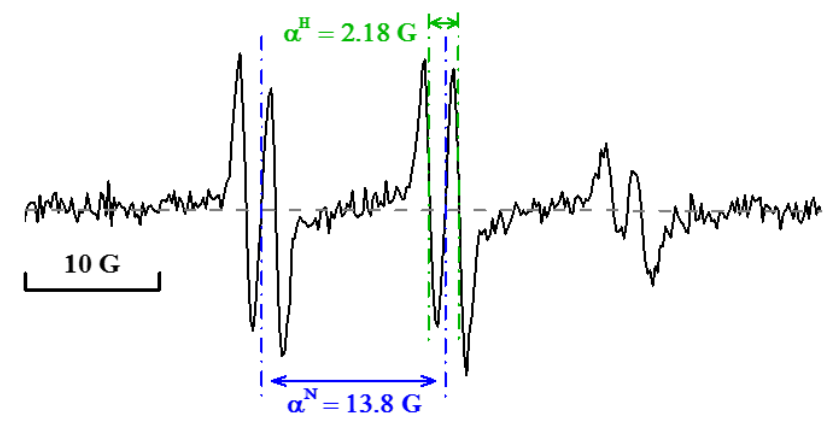

Fig. 4. EPR spectrum of radicals from low pressure gas-phase pyrolysis of $\mathrm{CnA}$ at $800{ }^{\circ} \mathrm{C}$ trapped by a solid phase spin trapping agent PBN ( $N$ - $t$-butyl- $\alpha$ phenylnitrone).

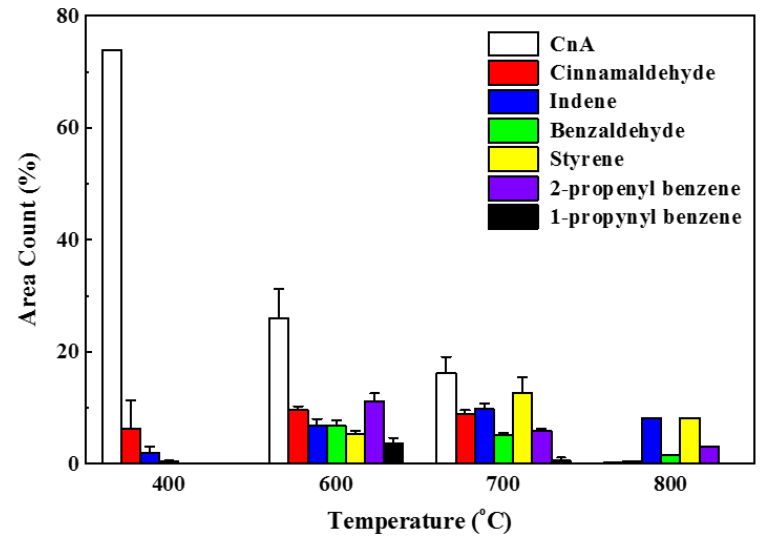

Fig. 5. Product distribution from pyrolysis of $\mathrm{CnA}$ at residence time of $0.2 \mathrm{~s}$ 


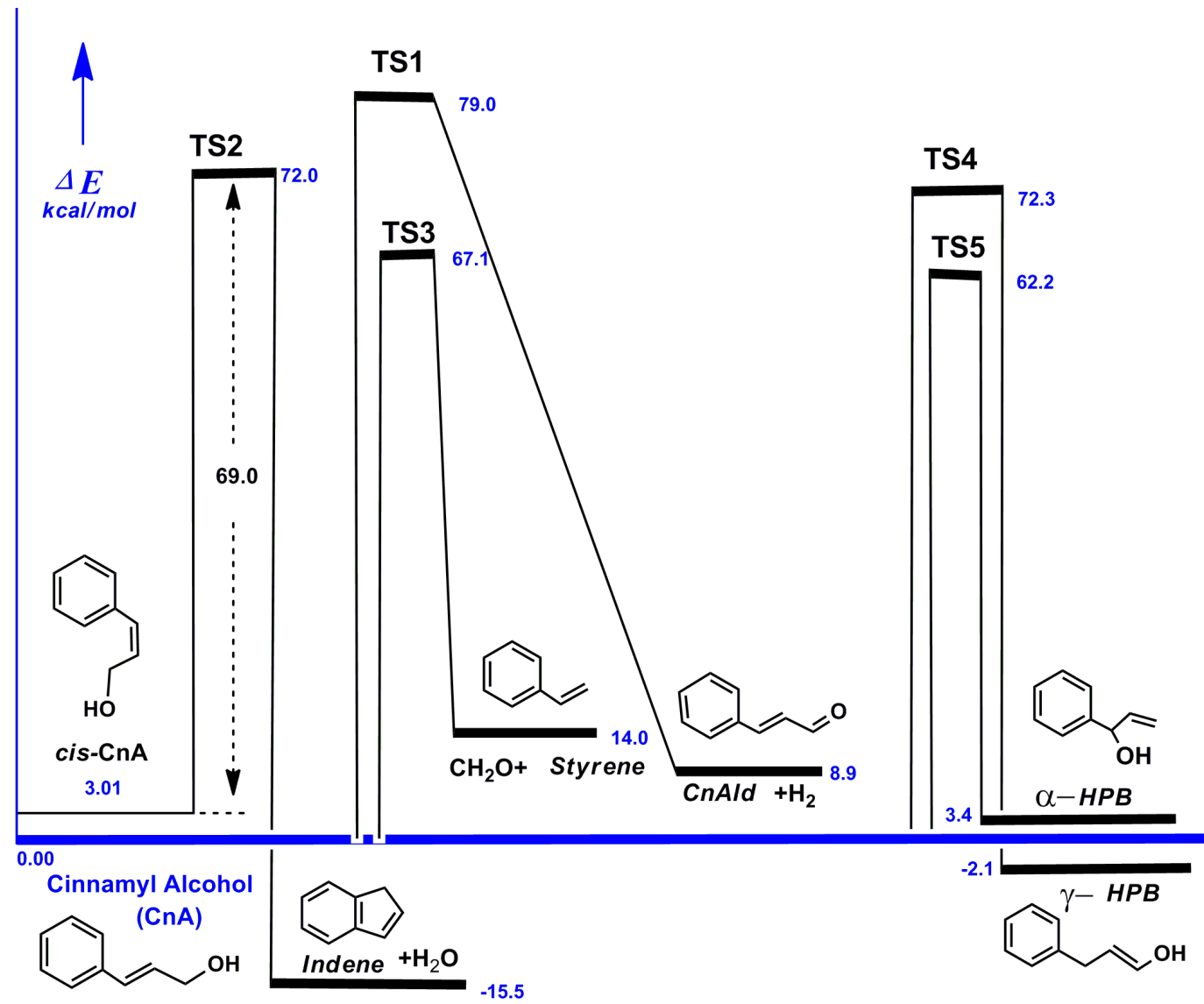

Fig. 6. Calculated unimolecular decomposition pathways for CnA. TS notations correspond to the reaction numbering. Total electronic energies $(\Delta \mathrm{E})$ are corrected with zero-point vibration energies. 


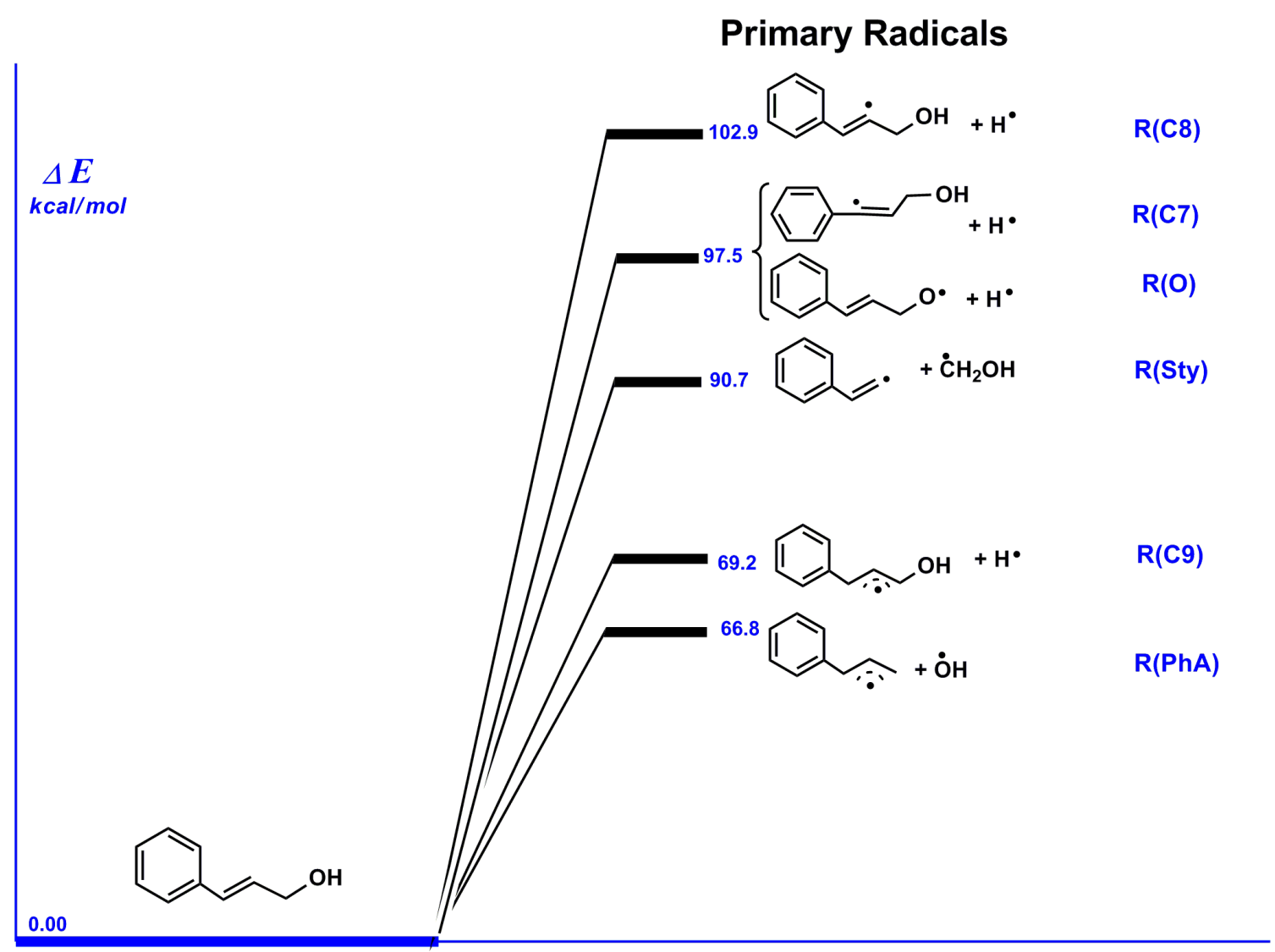

Cinnamyl Alcohol (CnA)

Fig. 7. Calculated bond-dissociation channels for $\mathrm{CnA}$ to generate primary radicals. The skeletal radicals are denoted by their core-atom numbers (ref. Fig. 1). $\mathrm{R}(\mathrm{Sty})$ and $\mathrm{R}(\mathrm{PhA})$ represent the terminal styrene and 1-phenylallyl radicals, respectively. 


(Cinnamyl Alcohol) $\left\{\begin{array}{l}\mathrm{C}_{6} \mathrm{H}_{5}-\mathrm{CH}=\mathrm{CH}-\mathrm{CHO}+\mathrm{H}_{2} \\ (\mathrm{Cynnamaldehyde)} \\ \mathrm{C}_{9} \mathrm{H}_{8}+\mathrm{H}_{2} \mathrm{O} \\ \text { (Indene) } \\ \mathrm{C}_{6} \mathrm{H}_{5}-\mathrm{CH}=\mathrm{CH}-\mathrm{CH}_{2}-\mathrm{OH} \mathrm{H}_{5}-\mathrm{CH}^{2} \mathrm{CH}_{2}+\mathrm{CH}_{2} \mathrm{O} \\ (\text { Styrene) } \\ \mathrm{C}_{6} \mathrm{H}_{5}-\mathrm{CH}_{2}-\mathrm{CH}=\mathrm{CH}-\mathrm{OH} \\ \left(\gamma-\mathrm{H}_{4} \text { droxy-propenyl-benzene) }\right. \\ \mathrm{C}_{6} \mathrm{H}_{5}-\mathrm{CH}(\mathrm{OH})-\mathrm{CH}=\mathrm{CH}_{2}\end{array}\right.$

633

634

635

636

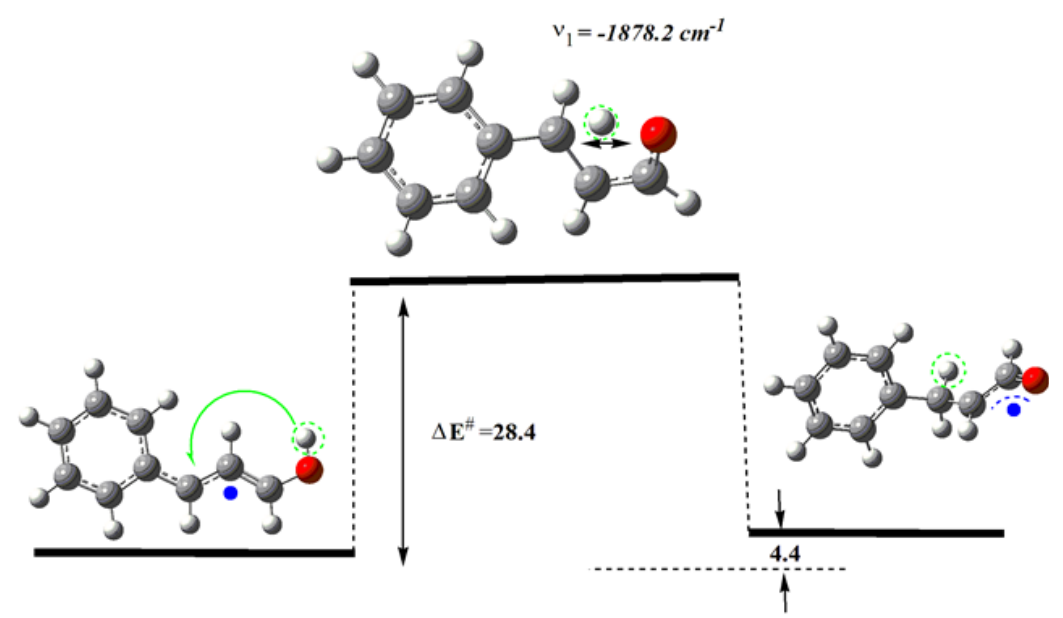

Fig. 8. Low-energy H-migration profile of $\mathrm{R}(\mathrm{C} 9)$ radical to form a terminal, oxygen-linked $\mathrm{C}_{6} \mathrm{H}_{5} \mathrm{CH}_{2}(\mathrm{CHCHO})^{\bullet}$ structure (reaction 7). 